REVISTA DE DERECHO UNED, NÚM. 8, 2011

\title{
BASES CONCEPTUALES DE LOS DERECHOS AMBIENTALES Y TRANSGENERACIONALES
}

\author{
CaYetano NúÑEZ Rivero \\ (UNED) \\ AleXANDER LuZARdo NAVA \\ Universidad Central de Venezuela. (UCV)
}

Resumen: Los Derechos ambientales y transgeneracionales emergieron con fuerza en el último tercio del siglo XX, procediéndose en un breve periodo de tiempo a su constitucionalización y proclamación mediante Tratados y Declaraciones internacionales. Sin embargo, tal auge no ha ido acompañado de una definición conceptual de los términos utilizados para su descripción, aspecto especialmente agravado en el idioma castellano, como consecuencia de la casi exclusiva utilización de la lengua inglesa en los foros internacionales de referencia, lo que ha posibilitado una cierta confusión y falta de homogeneidad, en la descripción de términos y conceptos, muchos de los cuáles no han sido todavía admitidos por la Real Academia de la Lengua. En el presente trabajo se intenta proceder a una definición conceptual de los mismos.

Palabras clave: Constitución, derechos transgeneracionales, ética ecológica, geopolítica ambiental, enfoque antropológico, paradigma antropocéntrico, enfoque ecoantropológico, sociodiversidad, sustentabilidad.

* El presente artículo se ha realizado en el marco del Proyecto de Investigación: «Constitución y Colaboración: Transformaciones del Estado Constitucional» N. ${ }^{\circ}$ DER 2009-10375, M. ${ }^{\circ}$ de Educación y Ciencia. 
Abstract: Environmental Rights and transgenerational emerged strongly in the last third of the twentieth century, proceeding in a short period of time to proclaim a constitution and by international treaties and declarations. However, this boom has not been accompanied by a conceptual definition of the terms used to describe it, which is particularly exacerbated in the Castilian language, as a result of the almost exclusive use of English in international reference, which has enabled some confusion and inconsistency in the description of terms and concepts, many of them have not yet been accepted by the Real Academia de la Lengua. this assay tries to proceed with a conceptual definition of them.

Key words: Constitution, trans-rights, environmental ethics, environmental geopolitical, anthropological approach, paradigm anthropocentric approach ecoantropológical, social diversity, sustainability.

Sumario: I. Ambiente. II .Áreas naturales protegidas. III .Civilizaciones . IV. Derechos transgeneracionales. V. Diversidad biológica. VI. Ética ecológica. VII. Fronteras ecológicas. VIII. Geopolítica ambiental. IX Paradigma antropocéntrico. X .Enfoque ecoantropológico. XI. Sociodiversidad. XII. Sustentabilidad, umbral de tolerancia y capacidad de carga. XIII. Desarrollismo. XIV. Impacto ambiental sociocultural. XV. Umbral de tolerancia y capacidad de carga. XVI. Pristinidad ecológica. XVII. Parques nacionales y reservas forestales. XVIII. Ordenación del territorio. XIX .Justicia ecológica y Justicia ecoantropológica. XX. Principio de preocupación ambiental. XXI. Demografía sustentable y ecología humana. XXII. Desarrollo social insustentable. XXIII. Comercio sustentable. XXIV. Transversalización axiológica del ambiente. XXV. Conciencia ecológica. XXVI. Bienes jurídicos ambientales.

\section{AMBIENTE}

El Diccionario de la Real Academia define el Ambiente como cualquier fluido que rodea al cuerpo, aire tranquilo que rodea los cuerpos, circunstancias que rodean las personas o cosas. Pero estas definiciones requieren ser ampliadas.

La Teoría General de los Sistemas que se remonta a E. G. Saint -Laire, define el término «milen ambitat», refiriéndose al medio exterior, como conjunto de factores naturales, que influyen en el desarrollo de los organismos, y con los cuales estos se desenvuelven a lo 
largo de toda su vida. Desde entonces los términos «Ambiente», «Medio Ambiente», "Medio» aparecen superpuestos, no solo en Ecología sino en otras ciencias. En los convenios, tratados, protocolos, declaraciones internacionales se utiliza en idioma ingles, o en francés con su expresión environnemet, pero al traducirse al castellano resulta casi un pleonasmo. De acuerdo con Folle en el Diccionario de Socioecología (Planeta 1993:213) «La Locución Medio Ambiente», también quiere decir «en la mitad del medio», «media mitad». En castellano, la palabra «ambiente» parece definitivamente más apropiada para tratar de conceptuar la complejidad subyacente.

Para la Conferencia de las Naciones Unidas sobre población del año 1974, los recursos se han clasificado comúnmente en renovables y no renovables. El aire, la tierra, los bosques y las pesquerías pertenecen a la primera categoría; los minerales y la mayor parte de las fuentes de energía, a la segunda. Sin embargo los principios físicos de la conservación de la materia hacen innecesario el concepto de recurso no renovable ${ }^{1}$.

El término Ambiente, va más allá del concepto de «Recursos Naturales», ya que este posee una connotación vinculada a la actividad económica y la explotación intensiva e ilimitada.

El Ambiente es un concepto que no puede ser definido hoy solo desde una perspectiva disciplinaria ya que es fundamentalmente una polidisciplina y una transdisciplina en la cual se articulan aportes de la Biología, Geografía, Geología, Geomorfología, Derecho Ambiental, Antropología, Sociología, Economía Ecológica, Cosmología, Climatología y la Nueva Prehistoria e Historia, además de los conocimientos de las propias comunidades.

Entre las premisas básicas subyacentes en el concepto matriz de Ambiente, es necesario incorporar los siguientes conceptos: sistema, interdependencia, totalidad, interacción, equilibrio holístico.

Definimos el ambiente como una totalidad independiente que permite el desarrollo de la vida, formando parte todos los recursos naturales, las diversas especies animales y vegetales que conviven en el planeta, incluyendo al hombre, la biodiversidad y todos los sistemas y procesos ecológicos. El ambiente está integrado también por el patrimonio histórico-cultural, paleo-ecológico, arqueológico, arquitectónico, espeleológico y espacial.

\footnotetext{
${ }^{1}$ Conferencia de las Naciones Unidas Sobre Población, 1979.
} 
El Ambiente en el marco del más reciente constitucionalismo, asume como premisas: 1) El carácter global planetario del equilibrio ecológico; 2) La protección de los bienes jurídicos ambientales, particularmente los parques nacionales, monumentos naturales, hábitat indígenas y demás áreas bajo régimen de administración especial; 3) El desarrollo ecológico, social y económicamente sustentable; 4) El principio de equidad transgeneracional; 5) La seguridad ambiental local, nacional y universal; 6) La Protección de la diversidad biológica, los procesos ecológicos esenciales, la protección de las aguas, el aire, las costas, los suelos, la capa de ozono, las especies vivas; 7) La ordenación del territorio; 8) La educación ambiental; 9) Limitaciones y regulaciones a la propiedad por razones ecológicas; 10) La promoción de la agricultura sustentable; 11) La protección de las aguas como bienes del dominio público y del ciclo hidrológico; 12) El rescate y conservación de las tierras de vocación agrícola; 13) El principio de prevención.

\section{II. ÁREAS NATURALES PROTEGIDAS}

Existen distintas categorías de preservación ambiental, decretados por los Estados nacionales y por las organizaciones internacionales, como la UNESCO-Naciones Unidas, que posee una Red Internacional de Reservas de Biosfera, bien por el equilibrio del medio ambiente y la reserva que supone para el futuro de la humanidad, bien por la protección de las comunidades humanas que allí viven, sin que ello suponga un deterioro del medio ambiente.

\section{CIVILIZACIONES}

Asumimos el concepto de Civilizaciones en plural planteado por Roberth Yaullinen en 1981 para referirnos a la diversidad de pueblos, etnias, naciones, sociedades y civilizaciones existentes o que han existido.

Aunque la palabra civilización casi siempre se asume en un sentido normativo lo cual supone una determinada apreciación en oposición a barbarie-animalidad, el esfuerzo de las ciencias sociales y del Derecho Internacional consiste en superar la tendencia de enfocar a las civilizaciones en función solo del observador. Se trata de trascender cierta visión histórica-lineal de la idea de progreso presente en autores como Spencer, Comte, Morgan y Marx. 
Oswaldo Spengler en su clásica obra «La Decadencia de Occidente» (1928) considera a la civilización como un conjunto de cosas más amplias que la cultura, que vendría a ser un aspecto superestructural-ideológico de aquella, es decir un conjunto de productos específicos (mitos, artes, religión).

Para el estructuralismo la cultura es un conjunto de relaciones simbólicas a todos los niveles. Nosotros, optamos por el concepto de Civilización en plural, acepción desarrollada por el pensamiento antropológico entre otros por Edwar Taylor, Levi-Strauss, Robert Yaullin, Darcy Ribero, Esteban Mosonyi, La UNESCO y demás órganos de las Naciones Unidas han reconocido la diversidad de culturas, pueblos y civilizaciones.

\section{DERECHOS TRANSGENERACIONALES}

Aquellos derechos que protegen no solo los intereses de la sociedad, sino que también preserva y conserva el equilibrio ecológico global y los bienes jurídicos ambientales como patrimonio común e irrenunciable de la humanidad, promueve la seguridad ambiental, los principios y criterios de ordenación democrática del territorio y las líneas estratégicas de sustentabilidad y sostenibilidad ecológica, social, económica y política, con enfoques ecoantropológicos y transdiciplinarios, que tiende a superar el antropocentrismo y el biocentrismo presente en los primeros enfoques de las ciencias sociales, económicas, biológicas y en el derecho clásico.

Los Derechos Transgeneracionales pueden ser concebidos en tres planos: derechos individuales, derechos colectivos y derechos de generaciones. El encabezamiento del artículo 127 de la Constitución Venezolana de 1999 asumió este criterio, cuando proclama «Es un derecho y un deber de cada generación proteger y mantener el ambiente en beneficio de sí mismo y del mismo futuro». Se inscriben entre los denominados derechos de tercera y cuarta generación, surgidos en la década del 70 del siglo XX tales como al derecho al ambiente, el derecho a la paz y el desarrollo sustentable. Los derechos transgeneracionales surgen a partir del año 1945, cuando por primera vez se utiliza la energía nuclear, con el lanzamiento de las bombas atómicas sobre Hiroschima y Nagasaki (Japón), previa realización de experimentos en 1944, del proyecto científico MANHATHAN. A tales efectos la Carta de las Naciones Unidas, aprobada en junio de 1945 comienza con una declaración de responsabilidad para con las generaciones futuras: «Nosotros, los pueblos de las Naciones Unidas, decidimos sal- 
var a las futuras generaciones del azote de la guerra...», veinte años después en 1972, la Conferencia Internacional sobre el Medio Humano de la Naciones Unidas celebrada en Estocolmo, aprueba la Stockholmo Declaration On The Human Envioroment, cuyo Preámbulo dice «defender y mejorar el medio ambiente para las generaciones presentes y futuras se ha considerado un imperativo para la humanidad». Para Jhon Rawls en su libro «Una Teoría de la Justicia» (1971, FCE) «Debemos ahora tomar en consideración la cuestión de la justicia entre generaciones. No hay necesidad de señalar las dificultades derivadas de este problema, el cual somete cualquier teoría ética a las pruebas estrictas por no decir imposibles».

Para Giuliano Pontara en «Ética y Generaciones Futuras» (1996, pág. 180) se trata de desarrollar una moral intergeneracional: 1) La aceptación de ésta en un código de moral positivo válido a nivel planetario que proporcione garantías razonables de que los intereses vitales de generaciones futuras se tomen en consideración equitativamente; 2) No tengamos exigencias tan elevadas para los sujetos agentes que resulten difícilmente interiorizables en gran escala.

«...creo que se debe destacar la importancia de la disposición para vernos nosotros mismos, individual y colectivamente, no como amos del planeta, o de esta o aquella parte del planeta, sino como administradores fiduciarios que de alguna manera deben rendir cuentas de su proceder a las generaciones siguientes». (Pontara 1996:180)

Estas disposiciones están ya incorporadas en diversas doctrinas éticas-religiosas, tales como la doctrina de Ghandi (1869-1948). Asimismo, en forma implícita en la base de la doctrina liberal de Jhon Locke, según la cual cada uno puede utilizar los recursos del planeta siempre, que se deje para otros tanto e igualmente bueno.

Para Pontara existen algunas normas de moral intergeneracional entre las que destaca:

1. No ejecutar elecciones que tengan consecuencias irreversibles o cuya irreversibilidad sea muy difícil o extremadamente costosa.

2. Esta norma supone abandonar la línea fundada en la energía nuclear y en la producción de energía de combustibles fósiles, a favor de una vía blanda, que tenga en su base el ahorro de energía y en la utilización de las fuentes alternativas.

3. Poner fin a la enorme destrucción forestal.

4. Maximizar el nivel de vida sostenible. 
5. Proteger la biodiversidad.

6. Proteger el patrimonio artístico, científico y cultural.

\section{DIVERSIDAD BIOLÓGICA}

La diversidad biológica está conformada por ecosistemas, especies y genes.

Es el acervo genético de una población, comunidad o ecosistema determinado. El acervo o variabilidad genética en un determinado ecosistema vendría determinado por el número de especies distintas que hay en el mismo, por el grado de parentesco de las distintas especies y por el grado de intercambio genético de los distintos miembros de una especie.

La diversidad está conformada también por el conocimiento que poseen las poblaciones indígenas y locales sobre los ecosistemas y su utilidad social.

\section{VI. ÉTICA ECOLÓGICA}

Constituye una reflexión de segundo orden sobre los problemas morales.

Para Cortinas y Martínez (1996). La pregunta básica de la moral sería entonces ¿Qué debemos hacer? Mientras que la cuestión central de la ética sería más bien ¿Por qué debemos? Es decir, qué argumentos avalan y sostienen el código moral que estamos aceptando como guía de conducta.

La ética nos obliga a tener presente las siguientes consideraciones y posiciones, fuera de toda neutralidad valorativa.

a) Denunciar o avalar según el caso determinado códigos morales.

b) También la ética puede conducir a recomendar determinado código como racionalmente preferible o aceptable.

c) La ética puede llegar a la conclusión de la pertinencia de varios aspectos de distintos códigos morales, por ejemplo aquellos valores presentes en distintas religiones «manteniéndose de este modo en pluralismo moral o mas o menos amplio». 
d) Asumir un método riguroso, aunque sin dogmatismo para hablar en serio de cualquier ámbito del saber.

La Ética es parte de la filosofía que, desde la antigua Grecia, se ocupa de los principios y preceptos que la conciencia humana se impone libremente para gobernar la conducta individual y regular las relaciones intersubjetivas.

Para Valencia Volla (2003) «Sin la Ética, el derecho no sería más que una ideología de dominación, una tecnología del conflicto».

En el pensamiento ecológico es necesario rescatar la carta del jefe indígena Seatly, dirigida al presidente de los Estados Unidos Franklin Pierce que en 1874 dijo: «pero ustedes caminarán hacia la destrucción rodeados de gloria, inspirados por la fuerza del Dios que los trajo a esta tierra y que, por algún designio especial, les dio dominio sobre ella y sobre el piel roja» «Termina la vida y comienza la supervivencia».

El autor norteamericano Arnold Leopold, desde la década de 1940 criticó el antropocentrismo moral excluyente que solo reconoce la naturaleza como un valor instrumental para fines y necesidades humanas.

Para el español Nicolás Sosa (2001) la teorización ética contemporánea debería efectuar una mirada hacia atrás (la tradición ética de la modernidad) para propiciar un salto hacia delante (la Ética Ecológica, acorde con el postulado de la sostenibilidad). El reto de la Ética es, por lo tanto, reintegrar, en el esquema de valores postulados por los éticos modernos (la igualdad social, la justicia distributiva, las responsabilidad), esta otra dimensión planetaria, ambiental, olvidada, superando la «ética determinista de la simplicidad». Repensar la justicia, pero entre los hombres y el resto de la Biosfera².

El surgimiento de la energía nuclear en 1944 y el particular de la bomba atómica, al final de la segunda Guerra Mundial, creó las posibilidades de la destrucción o eliminación de la vida sobre la tierra. Ya no se trataba de la desaparición de millares de personas por el uso del armamento de guerra, sino que ahora es posible la extinción biológica y ecológica, lo cual obliga a fundar una ética planetaria, que además de la crítica a la guerra, demanda una impugnación radical al uso y proliferación de armas nucleares, químicas, bacteriológicas y de terrorismo en cualquiera de sus formas. El pacifismo, es un movi-

${ }^{2}$ Nicolas Sosa (2002) a las Vueltas con la Sustentabilidad, esta vez desde una ética en sistema $\mathrm{N}^{\circ} 162$, 163. Editorial Fundación Sistema. Madrid. 
miento social, al igual que el ecologismo y la defensa de los derechos humanos, de alcance universal expresado en la formación de movimientos como el Green Peace y Amnistía Internacional, que al decir de Edgar Morín, representan la otra cara de la globalización.

Maurice Strong, Secretario General de la Cumbres de Estocolmo (1972) y Río de Janeiro-Cumbre de la Tierra (1992) al referirse al primer enfoque del Club de Roma, Los Límites del Crecimiento de 1972 señala:

Creo que la mayor contribución de «los límites del crecimiento es la que hace al hecho mismo de inducir a los hombres; particularmente, a sus dirigentes a tomar en sus manos el problema de cómo el hombre va a dirigir la primera civilización mundial de alta tecnología y la proliferación de complejas interdependencias que la tecnología misma ha producido. Nos ha hecho darnos cuenta, en forma muy simple, de que este sistema físico de interdependencias de que el hombre depende, es en realidad frágil, que ha de considerarse globalmente, y que debemos enfrentarnos a él y tratarlo como una unidad global ${ }^{3}$.

La idea de los límites del crecimiento vino a reforzar la Conferencia de Estocolmo, de las Naciones Unidas realizada entre el 5 y el 16 de junio de 1972.

Las bases de la ética ecológica quedaron asentadas en la Declaración del Principio de la Cumbre de la Tierra celebrada entre el 3 y el 14 de junio de 1992. Previamente las Naciones Unidas, celebraron en 1990, la Cumbre Mundial de la Infancia y se elaboró el informe de la Comisión del Sur (1990) que presidió Julios Ram Barage Nyerere. Entre 1990-1996 se celebraron también la Conferencia Mundial de Derechos Humanos (1993), la Conferencia Sobre Población y Desarrollo (1994), la Cumbre Mundial Sobre Desarrollo Social (1995), la Cuarta Conferencia Mundial Sobre la Mujer (1995), la Segunda Conferencia de las Naciones Unidas Sobre los Asentamientos Humanos (Hábitat) 1996, la Cumbre Mundial Sobre la Alimentación (1996), la Conferencia Mundial Sobre el Desarrollo Sostenible de los Pequeños Estados Insulares en Desarrollo (1994), la Conferencia Mundial sobre la Reducción de los Desastres Naturales (1994), Novena Conferencia de las Naciones Unidas Sobre Comercio y Desarrollo, Noveno Congreso Sobre Prevención del Delito y Tratamiento de Delincuentes 1995, la Conferencia Mundial de Johannesburgo 2002.

${ }^{3}$ Maurice Strong (1973) Entrevista por Pillen Oltmans «Debates Sobre el Crecimiento». Fondo de Cultura Económica. México. pág. 224. 
En la Declaración de Río 92 figuran entre sus principios I) La erradicación de la pobreza y la reducción de las disparidades en los niveles de vida en todo el mundo son requisitos indispensables para el desarrollo, II) los países desarrollados reconocen la responsabilidad que les cabe en la búsqueda internacional del desarrollo sostenible o sustentable, en vista de las previsiones que las sociedades ejercen en el ambiente mundial y las tecnologías y los recursos de que disponen.

En la actualidad otro de los temas se refiere a los principios bioéticos referidos a los derechos de los seres humanos contra la probable clonación de seres humanos y los impactos de la biomedicina y la ingeniería genética con el desciframiento del Código Genético de los seres vivos y sus consecuencias para la sociedad y el futuro de las especies.

Según Cortina y Martínez (2002) «Existe un gran acuerdo en que el problema ecológico, como ocurre también con el hombre, no es un problema técnico, sino moral».

Un imperativo moral para avanzar en el reconocimiento efectivo de los derechos humanos, el derecho a un ambiente sano y seguro, que forman parte de los llamados derechos de tercera generación, ya que los derechos de primera generación surgieron con la Revolución Norteamericana en 1776 y la Francesa de 1789 y sus primeras constituciones, mientras que los derechos de segunda generación, los derechos sociales, se consagraron en la Constitución Mexicana de 1917 antes que la Constitución Soviética de 1918.

Los derechos ecológicos o ambientales de tercera generación, que nosotros denominamos derechos transgeneracionales.

La palabra «Ética» procede del griego Ethos que significa originalmente «Morada» «Lugar en donde vivimos» pero posteriormente pasó a significar "el carácter», el «modo de ser» que una persona o grupo va adquiriendo a lo largo de su vida. Por su parte el término «Moral» procede del latín «mosi moris» que originalmente significaba «costumbre», pero que luego pasó a significar también «carácter» o «modo de ser». De este modo, «Ética» y «Moral» confluyen etimológicamente en un significado casi idéntico: todo aquello que se refiere al modo de ser o carácter adquirido como resultado de poner en práctica mas costumbres o hábitos considerados buenos.

Los términos Ética y Moral aparecen como intercambiables y en castellano se ha generalizado su uso como sinónimos. Cortinas y Martínez (1996) sin embargo consideran necesario, utilizar Ética para referirnos a la Filosofía Moral y Moral para denotar los distintos 
códigos morales concretos, serían entonces dos niveles diferentes de reflexión.

\section{FRONTERAS ECOLÓGICAS}

Las fronteras se definen como aquellas porciones del territorio o del espacio geográfico, en la cual convergen límites entre dos países, o entidades federales según sea el caso y en las cuales pueden existir ciudades, pueblos o comunidades vecinas, incluso pertenecientes a una misma etnia o pueblo.

Existen fronteras con actividades comerciales permanentes de gran intensidad mientras que en otros predominan los límites físicos bien sean fluviales, marítimos o terrestres, incluyendo sistemas montañosos o mesetas.

Según algunos autores debe establecerse separación entre los conceptos de fronteras y límites. La primera supone presencia de población y actividades económicas; la segunda podría tener como ejemplo los límites amazónicos de los Estados sudamericanos En todo caso, existen diferencias sobre la densidad demográfica y la actividad económica comercial.

Sostenemos que gran número de las fronteras, especialmente en el continente iberoamericano no deben ser definidas como espacios vacíos, pues allí existe una gran diversidad biológica y presencia de pueblos indígenas u otras comunidades indígenas con una dispersión estratégica, adaptada a las condiciones especiales del ambiente. En el caso del Amazonas, observamos que esta es una frontera biogeográfica indivisible, con presencia de bosques tropicales húmedos, ecosistemas escasos en el planeta y de una gran biodiversidad y que demandan protección nacional e internacional.

En América, las fronteras actuales y límites, se constituyeron a partir de 1492, con el proceso de conquista y colonización que desarticuló pueblos, etnias y culturas, y sus dominios territoriales conformando nuevas formas de organización denominadas virreinatos y capitanías en el caso de España y Portugal. Los ingleses en el territorio actual de Estados Unidos y Canadá y algunas islas del Caribe, al igual que Holanda y Francia, que se reubicaron en algunas islas y las Guyanas.

Para el mexicano Leopoldo Zea, en la Grecia antigua se determinó el tamaño y el alcance de las fronteras con la polis. 
Los límites y amplitud de esta última están establecidos por la vista, es decir, por lo que se podía observar desde lo más alto, y lo que no se podía contemplar, era considerado como el vacío, lo que no se puede hablar ni tampoco definir solo Dios puede ver todo, saber todo y controlar todo, Atenas, Esparta, Tebas, y muchas otras ciudades-estado griegas fueron creadas así. Las fronteras se extendían o disminuían con las guerras, como las del Peloponeso. Un pueblo marginal, Macedonia, originó la concepción imperial extendiendo las fronteras ${ }^{4}$.

Su expresión máxima fue Alejandro Magno, quien se planteó el proyecto expansionista asomándose como el «Dios mismo» que debería ir más allá de la barbarie, definidos como bárbaros, aquellos que no hablaban griego.

Alejandro de Macedonia extendió su frontera llegando hasta Persia y la India.

Grecia helenizó el mediterráneo y la diversidad de gente, razas y culturas. Tiempo después, Roma, hija del troyano Eneas, latinizó lo que Grecia había helenizado pero no alcanzó a helenizar al norte del mediterráneo, asimilando a otros bárbaros. Avanzando el Imperio, Roma se hizo acompañar de la religión integradora de dioses: el cristianismo ${ }^{5}$.

España, heredera de Grecia y Roma a partir de 1492, se lanzó en busca de nuevas tierras y riquezas y el proyecto salvacionista religioso católico, seguida de la Europa báltica y noratlántica.

En el norte del continente predominó la América anglosajona, protestante y puritana y al sur la denominada actualmente América Latina.

En el discurso de los fundadores de los Estados Unidos estuvo presente la idea expansionista, ente otros Tomas Jefferson, James Monroe, y Abrahán Lincon, que se evidenció en la anexión de gran parte del territorio Mexicano en 1847, que modificó las fronteras y un racismo, incompatible con la Constitución Norteamericana.

En el ensayo "Epistemología del Concepto de Frontera», el autor Alberto Saladino García (UNAN-México 2002) señala que «el campo semántico del concepto de Frontera se ha venido ampliando del ám-

\footnotetext{
${ }^{4}$ Leopoldo Zea (2002). La Frontera en la Globalización, en Latinoamérica en la Globalización y el Tercer Milenio. Compiladores. Leopoldo Zea y Hernan Taborda. Fondo de Cultura Económica. UNESCO, Instituto Panamericano de Geografía e Historia. México. pág 6

${ }^{5}$ Leopoldo Zea (2002). Ob. Cit. pág. 6.
} 
bito físico-geográfico a otras esferas, como la cultural y sus usos mas recurrentes han sido en las áreas de la ciencia y la filosofía» ${ }^{6}$.

Existe la perspectiva que ha marcado la globalización, por un lado como tendencia a la homogeneización cultural y por otro lado con el surgimiento y difusión de «los perfiles antropológicos» según la clásica expresión de Jacques Berque, de 1964. Este proceso comienza particularmente con la televisión, la era espacial en 1957 con el primer Spunik soviético lanzado al espacio, el satélite Startard en 1962, y la llegada del hombre a la luna, que convierte al planeta en una frontera espacial, Podríamos afirmar que existe una dialéctica de la globalización, las fronteras físicas y los perfiles ecoantropológicos que incluye la posibilidad de la superación del paradigma ópticolumínico y la construcción de naturalezas artificiales, lo cual reactiva nuevas y viejas transdisciplinas como la cosmogonía.

En el ámbito de las realidades sociales es necesario refundir el concepto fronteras a la luz de los conceptos de tolerancia, pluralismo cultural y lingüístico, convivencia y diálogo de civilizaciones, preservación de la diversidad biológica, el equilibrio ecológico global y local y la defensa de los derechos humanos y transgeneracionales, superando el esquema expansionista y totalitario, presente en los proyectos coloniales, fundamentalistas, economicistas e ideológicos.

En el caso de América Latina la conformación de los derechos de los pueblos indígenas en las constituciones de Brasil, Colombia, Paraguay, Argentina, Guatemala y Venezuela constituye un avance importante en la revalorización de pueblos sometidos a la colonización y la exclusión tanto por los imperios del siglo XV al XIX, como por los propios estados nacionales constituidos en el siglo XIX y XX, discusión esta, que aun tiene su manifestación entre los pueblos indígenas mexicanos y bolivianos, entre otros, que obliga a una discusión amplia y dirigida a los fines de no facilitar la balcanización del continente.

En la declaración de Barbados de 1971, el grupo de antropólogos conformados por Darcy Ribeiro, Guillermo Castillo Cárdenas, Esteban Mosonyi y Nelly Arvelo, entre otros, asumieron el planteamiento del concepto de Etnia que no tiene por qué desaparecer ante la existencia de los estados nacionales, ni en los proyectos clasistas y etnocidas.

\footnotetext{
${ }^{6}$ Alberto Saladino (2002) Epistemología del Concepto de Fronteras en Latinoamérica en la Globalización y el Tercer Milenio. Compiladores. Leopoldo Zea y Hernan. Taborda. Fondo de Cultura Económica. UNESCO, Instituto Panamericano de Geografía e Historia. México. pág. 17.
} 
Hoy a luz de la experiencia vivida en los casos de Camboya, Ruanda y la ex Yugoslavia, es necesario tener presente que, incluso entre etnias o pueblos oprimidos, también se pueden desatar etnocentrismo y racismo extremo.

El mestizaje, asumido como proyecto irreversible presente en la gran mayoría de los autores, da la impresión de desconocer la especificidad y vigencia de las múltiples culturas y procesos multilíneales del desarrollo histórico de los pueblos. El concepto de "raza cósmica» de Vasconcelos, se inscribe en una visión homegenizadora que no valora plenamente la vigencia de la diversidad humana, incluso la misma proclama de Bolívar en la Carta de Jamaica «No somos indios, no somos europeos, sino una especie media entre los legítimos propietarios del país y los usurpadores españoles...»

En realidad, hubiera sido más correcto decir « también somos indios, españoles, europeos y africanos, y muchos pueblos indígenas mantuvieron sus idiomas y evolucionaron en sus perspectivas societarias. La insurgencia del mundo indígena en México, Centroamérica y especialmente Bolivia, con el triunfo de Evo Morales, puso en evidencia que no eran una rémora del pasado, sino que están presentes como actores políticos, sin que ello signifique que sus propuestas políticas sean compartidas totalmente.

El mestizaje es múltiple. No se debe asumir el diseño de un mestizaje compulsivo, que niegue la existencia o el derecho a la diversidad humana, teniendo presente que el término raza, es una construcción cultural y que desde el punto de vista genético, casi todos los grupos humanos, han vivido un proceso de encuentro, desde el comienzo de la víspera humana, hasta nuestro días, pero bajo ninguna circunstancia niega la creatividad humana permanente, en el doble sentido biológico y sociocultural.

Podríamos decir que los grupos humanos; etnias, pueblos, naciones, tienden a constituirse en proyectos históricos, a través de un largo proceso de adaptación ecológica que va delineando un espacio vital y una serie de perfiles antropológicos y lingüísticos, que se pueden expresar en fronteras, abiertas o cerradas y con tendencias etnocéntricas, que en determinadas circunstancias se han convertido en patologías hipernacionalistas, etnocidas y hasta genocidas como se ha demostrado no solo en el caso del fascismo, el nazismo, el genocidio contra los armenios, o los recientes genocidios de Ruanda por grupos étnicos o los odios milenarios en la antigua Yugoslavia, o entre palestinos y judíos. 
El gran reto es encontrar la senda del diálogo de civilizaciones y culturas, concibiendo la tierra como Gaia o tierra patria (Morin) pero respetando la convivencia en los espacios étnicos y socioculturales, entendidos también estos como proyectos interculturales. Recientemente (septiembre 2004) el presidente del Gobierno español José Luís Rodríguez Zapatero planteó la necesidad de promover una Alianza de Civilizaciones. Ello supone también entender y respetar las creaciones y aportes del liberalismo clásico, especialmente en el constitucionalismo, los derechos humanos incluso del propio desarrollo capitalista con sus grandes y decisivos desarrollos científicos-tecnológicos en el marco de la ética de la tierra.

Roger Garaudy que publicó en el año 1977, el famoso libro «Diálogo de Civilizaciones», señala que la denominada cultura occidental, tuvo su nacimiento en Mesopotamia (Asia) y en Egipto (África).

«Si nos negamos a considerar occidente como una entidad geográfica, y lo miremos como un estado de ánimo orientado a la dominación de la naturaleza y de los hombres, semejante visión del mundo se remonta a la primera civilización conocida, lo que vio la luz en el delta del Tigris y el Eufrates en Mesopotamia (el Irak de hoy).

El nacimiento de nuestra civilización, caracterizada por una voluntad de poder y de dominación, encuentra su expresión literaria en la epopeya de Gilgmesh, mil quinientos años antes de la Iliada.

Allá se ha alzado el telón sobre el primer acto de nuestra historia. Esta primera epopeya se desarrolla en Gilgzmesh. El hombre domina a la naturaleza, lucha contra sus semejantes y trata de sobre pasar sus propios límites»

\section{GEOPOLÍTICA AMBIENTAL}

Definimos Geopolítica Ambiental como el enfoque interdisciplinario y transdisciplinario de las relaciones entre el ambiente como totalidad interdependiente con los pueblos, comunidades, cuya vocación no debe ser expansiva sino de convivencia con el ecosistema. Se trata de una Geopolítica que incorpora el territorio-espacio geográfico, con los valores de las pristinidad ecológica. Se destaca que en el caso de la Amazonia. Los conceptos de Cuenca hidrográfica y Cuenca visual, son vinculantes para comprender la dinámica del bosque húmedo tropical, su conservación y unidad. 
Se diferencia de la Geopolítica expansiva, etnocéntrica y totalitaria porque auspicia el interculturalismo y la visión transcultural, y pretende superar tanto el biocentrismo como el antropocentrismo. Se aplica el concepto de Geopolítica Ambiental preferentemente en biorregiones como la cuenca amazónica, por la importancia estratégica que posee para todo el planeta y los países que integran esta región.

\section{PARADIGMA ANTROPOCÉNTRICO}

El Paradigma Antropocéntrico hunde sus postulados en la cosmovisión Judeo Cristiana y también Islámica de dominio sobre la naturaleza. Según este paradigma, el hombre «es dueño y señor de la creación» tal como se expresa el Génesis, en la Biblia. El Antropocentrismo ha dominado en la sociedad occidental con el desarrollo científico-técnico y abarca tanto las ciencias físico-naturales como las ciencias sociales y humanas, manifestándose, asimismo en las políticas públicas y los planes de desarrollo.

\section{ENFOQUE ECOANTROPOLÓGICO}

El Enfoque Ecoantropológico pretende avanzar con respecto a los enfoques antropocéntrico y biocéntrico. Con el Paradigma Ecoantropológico surgen nuevos problemas que deben ser abordados por nuevas ciencias poli y transdisciplinarias.

El Enfoque Ecoantropológico, rescata el carácter matricial de la tierra para la vida y de la vida para la humanidad y abandona la idea de dominio de la naturaleza. La tierra se concibe como totalidad física, biológica y antropológica. El Enfoque Ecoantropológico reconoce la presencia de la especie humana a lo largo de la historia de la humanidad desde la diáspara que partió de África hasta llegar incluso al espacio exterior con sus desarrollos científico-técnicos, cuestión que obliga a establecer límites al «afán de poder», una convivencia entre la «naturaleza» y la supranaturaleza o tecnósfera.

\section{SOCIODIVERSIDAD}

La Sociodiversidad terminó acuñado originalmente por el lingüista Esteban Mosonyi el 9 de octubre de 1994, en la ciudad de Maracay, define la diversidad cultural, lingüística y societaria de la humanidad. 
Asume la diferencialidad inmanente y la diferencia como un derecho de los pueblos que incluye el respeto a sus procesos de adaptación ecológica y el conocimiento de la diversidad biológica y la memoria colectiva de las culturas y civilizaciones.

\section{SUSTENTABILIDAD}

La Sustentabilidad es el paradigma que pretende redefinir la clásico concepción del crecimiento sin atender a los límites que establece la base de recursos y los características de los ecosistemas.

La Sustentabilidad, tiene como uno de sus fundamentos teóricos e históricos, el primer informe del Club de Roma, en su clásico estudio «Los Límites del Crecimiento» (1970). Su mensaje básico: «que es imposible el crecimiento ilimitado en un sistema limitado», es el pilar del pensamiento verde.

Aunque algunas de las predicciones del informe no alcanzaron el dramatismo con el cual se anunciaron las consecuencias del modelo de desarrollo imperante en el planeta, sin embargo desató un movimiento institucional, social, ambiental, político, que se expresó en la revisión de los fundamentos del desarrollo, y en la puesta en práctica de nuevas tecnologías, creación de agencias y ministerios del ambiente en más de cien países, convenios, tratados, declaraciones, protocolos internacionales, reformas de las constituciones y leyes que establecen hoy los derechos, deberes ambientales y las regulaciones técnicas respectivas.

En 1992, el grupo del Club de Roma, elaboró un nuevo estudio denominado "Más allá de los Límites del Crecimiento» en el cual se ratifican sus planteamientos centrales, aun con las revisiones y errores admitidos del informe de 1970.

1. Si las actuales tendencias de crecimiento de la población mundial, la industrialización, la contaminación, la producción de alimentos y el agotamiento de recursos continua sin cambios, los límites de crecimiento del planeta se alcanzaran antes de cien años. El resultado más probable será un descenso incontrolable y repentino tanto de la población como de la capacidad industrial.

2. Es posible alterar esas tendencias de crecimiento y establecer un marco de estabilidad económica y ecológica que sea sostenible en el futuro. El estado de equilibrio global puede ser diseñado de forma que las necesidades materiales básicas de toda persona tenga las 
mismas oportunidades para desarrollar su potencial humano individual.

3. Si la gente del mundo decide luchar en ese sentido, y no en el primero, cuanto más pronto comience a trabajar para lograrlo mayores serán sus posibilidades de éxito.

El crecimiento de la población, producción de alimentos, industrialización, contaminación y consumo de recursos no renovables, continúa en forma exponencial.

El desarrollo sostenible definido por la Comisión Sobre el Medio Ambiente y Desarrollo de las Naciones Unidas presidida por Gro Harlen Brundtand en 1987; en el informe «Nuestro Futuro Común, lo define como un proceso de crecimiento económico, acompañados de cambios de estructuras económicas y sociales, pero que, a la vez satisface las necesidades de las generaciones futuras para satisfacer las propias necesidades».

Para que un modelo de desarrollo sea considerado sostenible o sustentable debe cumplir-según el informe Brundtand tres condiciones:

- Que la tasa de uso de los recursos naturales sea inferior a su tasa de regeneración.

- Que el aprovechamiento de los recursos no renovables se lleve a cabo a menos velocidad que los que necesitan los sistemas naturales para la asimilación de los mismos.

- Que la liberación de elementos contaminantes al ambiente, se produzca a menor velocidad de la que necesitan los sistemas naturales para la asimilación y neutralización de los mismos.

En junio de 1992 se llevó a cabo la Conferencia de las Naciones Unidas Sobre Medio Ambiente y Desarrollo, celebrada en Río de Janeiro, Brasil. Fueron aprobados cuatro documentos básicos La Agenda 21 o Plan de Acción, La Declaración de Río que contiene 27 principios; La Convención Marco de las Naciones Unidas Sobre el Cambio Climático y el Convenio Sobre Diversidad Biológica.

El principió $\mathrm{N}^{\mathrm{o}} 3$ dice que «El derecho al desarrollo debe ejercerse de forma que responda de forma equitativa a las necesidades de desarrollo y ambientales de las generaciones presentes y futuras». El principio $\mathrm{N}^{\mathrm{o}} 8$ establece que «para alcanzar el desarrollo sostenible y una mejor calidad de vida para todas las personas, los estados deben reducir o eliminar las modalidades de producción y consumo insostenibles». 
La declaración es una propuesta global de reforma de la sociedad y economía en el marco de la participación democrática.

El desarrollo sustentable debe realizarse en forma integrada y no aislada, siendo uno de los objetivos esenciales la erradicación de la pobreza y conservar los ecosistemas de la tierra.

La Conferencia sobre Desarrollo Sostenible de Johannesburgo de las Naciones Unidas (RIO+10) ratificó la declaración de principios de Río y el programa de la agenda 21, haciendo énfasis en los problemas de pobreza, agua, sobrecrecimiento, salud, como cuestiones esenciales del desarrollo sustentable.

El origen del concepto del Desarrollo Sostenible o Sustentable, se remonta a finales de los años 70 del siglo XX, en Estados Unidos, referido a una conducta política y a un comportamiento empresarial que haga factible cumplir los objetivos del crecimiento económico, al mismo tiempo que garantce la protección del ambiente. «El Desarrollo Sostenible no es una opción para la empresa sino una exigencia para su propia existencia y su única oportunidad para competir en un mercado transnacional donde solo pueden entrar los productos respetuosos con el medio ambiente o fabricados con este criterio ecológico. Ello obliga a crear una política corporativa medioambiental, revisarla para que cumpla con sus objetivos prefijados y desarrollar un plan estratégico.

En Estados Unidos la auditoria ambiental está respaldada por agencias de impacto ambiental (EPA) y la comisión de valores bursátiles la hace obligatoria para la cotización en la bolsa de empresas.

En Europa la tradición se remonta al año 1984 y fue Holanda el primer país en adaptarla. El etiquetado ecológico es una práctica común en Europa y progresivamente han asumido los Sistemas de Gestión Ambiental ISO 14.000.

En otros países, el tema se ha constitucionalizado, valga el ejemplo de Venezuela, donde la Constitución de 1999, acogió el principio de sustentabilidad en el título correspondiente a los Derechos Humanos y garantías, en el título sobre el Régimen Económico y el título sobre la Seguridad de la Nación.

\section{DESARROLLISMO}

Cuestionamos una concepción del desarrollo que promueve un estatismo depredador, vinculado también al interés de empresas tras- 
nacionales, incluso con intereses de gobiernos regionales o locales, que buscan afanosamente la obtención de recursos en forma inmediata. Se estrechan vínculos entre concepciones desarrollistas que liquidan a mediano y largo plazo las bases biológicas y ecológicas de un posible desarrollo sustentable. Rebasa el Umbral de Tolerancia y la Capacidad de Carga de los Ecosistemas. Se produce entonces un Sobrebasamiento, término acuñado en el Informe del Club de Roma del año 1992.

\section{IMPACTO AMBIENTAL Y SOCIOCULTURAL}

El Concepto de impacto ambiental ha ido así cambiando a lo largo de estos años de polémica sobre el tema, que en síntesis iría desde un enfoque casi exclusivamente biofísico y reduccionista en las políticas conservacionistas de los sesenta y setenta, a una concepción del medioambiente más amplia e integrada, en donde lo social juega un papel fundamental en la configuración de lo que se viene a llamar problemática medioambiental ${ }^{7}$.

El estudio y evolución de impacto ambiental requiere de la participación de la comunidad en el proceso de definición y decisión de impacto y el análisis del impacto social y cultural de los proyecto de desarrollo en lo que podríamos caracterizar como un enfoque socioambiental en una perspectiva que no se reduce a los conceptos físicos-naturales; pues incorpora las creaciones sociales, étnicas, culturales, lingüísticas en una interacción con el ambiente a través de un proceso de ensayo y error milenario, pero también teniendo presente las rupturas, cambios históricos y tecnológicos. Se trata de destacar también los procesos de adaptación ecológicos, climáticos y geológicos, la evolución biológica y los desarrollos culturales pero en una dinámica recursiva e interactiva, que puede significar avances, retrocesos, involuciones o fenómenos no controlados por una sociedad determinada, ante los embates históricos. Los «hechos sociales» introducen cambios en el ambiente, los recrean, pero también pueden tornarse destructivos o insustentables, por el agotamiento de la base de recursos por extinción de las vida colectiva por las propias creaciones humanas, por ejemplo la energía nuclear y los procesos económicos e industriales que sobrepasen los límites.

${ }^{7}$ Mercedes Pardo (1994) Impacto Social de las Evaluaciones de Impacto Ambiental. Su Conceptualización y Práctica. Universidad Pública de Navarra. Revista Española de Investigaciones Sociológicas. Abril - junio, No 66. pág. 145. 
La evaluación del impacto ambiental puede conllevar a determinar los efectos negativos de una obra pública en los ecosistemas, aunque desde cierto punto de vista podría justificarse por razones económicas y sociales, sin embargo, la tendencia es a establecer la prevención a fin de evitar daños irreparables, o restituir las condiciones originales, cuando ello sea posible, o en todo caso, minimizar o reparar el daño ecológico. En cualquier circunstancia se estudia el nivel de viabilidad y la rentabilidad ecológica, económica y social.

El Consejo Económico y Social, de las Naciones Unidas en la Asamblea General (periodo de sesiones sustantivo de 1992) al referirse a la evaluación del impacto ambiental, el informe del Secretario General Bautros Ghali señaló:

«La Evaluación del impacto ambiental, ha sido el instrumento primordial para la adopción de decisiones con respecto a la conservación del medio ambiente a nivel de proyecto». (ONU-Consejo Económico Social, 15 de abril de 1992) ${ }^{8}$.

El estudio y evaluación de impacto ambiental establece alternativas ante una obra o proyectos susceptibles de generar graves impactos. Ejemplo: el caso de una megarrepresa ante la cual se presentase la posibilidad de varios embalses pequeños. Asimismo ante los tendidos eléctricos, los desarrollos petroleros, urbanos, agrícolas, etcétera.

Un estudio de impacto ambiental en su primera fase incluye análisis característicos del Proyecto, análisis característicos del medio. En la segunda fase Identificación y Valoración de Impactos, medidas correctivas y la tercera fase un plan de vigilancia ambiental.

En España la Declaración de Impacto Ambiental (DIA) es el documento oficial legal, publicado en el Boletín Oficial del Estado y es vinculante en sus condiciones, teniendo que reflejar el proceso de evaluación de impacto ambiental en todos sus aspectos: consultas previas, estudio de impacto ambiental, medidas correctoras, plan de vigilancia ambiental, proceso de participación pública. Tiene finalmente, que establecer «las condiciones ambientales del proyecto, es decir la aprobación del proyecto sometida a aquellos aspectos ambientales que obligatoriamente tiene que ampliar». (Pardo, 150: $1994)^{9}$

\footnotetext{
${ }^{8}$ Boutros Ghali (1992) ONU. Consejo Económico Social, 15 de abril de 1992. Informe Asamblea General de las Naciones Unidas. New York.

9 Mercedes Pardo (1994) Impacto Social de las Evaluaciones de Impacto Ambiental. Su Conceptualización y Práctica. Universidad Pública de Navarra en Reis, Revista Española de Investigaciones Sociológicas. Abril-Junio, nº 66.
} 
La evaluación debe considerar la capacidad de carga de los ecosistemas, que requieren de un conocimiento de la fragilidad o no, tipo de suelo, pristinidad ecológica, potencialidades de recursos, existencia de acuíferos.

\section{UMBRAL DE TOLERANCIA Y CAPACIDAD DE CARGA}

El umbral de tolerancia se refiere al momento en que determinada intervención traspasa el equilibrio de la capacidad de sostén del ecosistema o del espacio geográfico, ante obras, proyectos o intervenciones que puedan afectarlo o desnaturalizar sus condiciones físicas, biológicas, ecológicas, culturales y arqueológicas ${ }^{10}$.

Donela Meadows, Dennis L. Meadows y J. Rander en «Más Allá de los Límites del Crecimiento» (1992), escrito a veinte años del Informe Los Límites del Crecimiento (1972), ambos del Club de Roma, utilizan el concepto de Sobrepasamiento ${ }^{11}$. La escala que utiliza es planetaria, en la cual la población humana y la economía extraen recursos de la tierra y emiten desperdicios contaminantes hacia el ambiente «muchas de esas tasas de extracción y emisión han crecido hasta magnitudes insoportables. El medio ambiente ya no lo puede sostener. La sociedad humana ha sobrepasado sus límites por los mismos motivos que otros sobrepasamientos se producen. Los cambios son demasiado rápidos. Las señales aparecen tarde, son incompletas, están distorsionadas, son ignoradas o se les niega. La inercia es grande. Las respuestas son lentas». (Meadows, Rander; 30: 1992)12

${ }^{10}$ La capacidad de sustentación es el tamaño de población que puede ser sostenida indefinidamente por el ambiente; el concepto de capacidad de sustentación incluye los diversos recursos que la sociedad utiliza del ambiente, los diversos tipos de residuos que devuelven y la gran variabilidad de tecnologías, instituciones y estilos de vida. La capacidad de sustentación es un concepto dinámico, no es constante, está sometido a cambios con el clima y otros factores externos así como la presión que ejercen las distintas especies sustentadas.

${ }^{11}$ Sobrepasamiento en Más Allá de los Límites del Crecimiento (1992)el nuevo Informe del Club de Roma que revisa 20 años desde la publicación del año 1972 (Los Límites del Crecimiento) es un término derivado del inglés Overshoot, utilizado en el análisis de sistemas que significó pasarse de un objetivo, ir más allá de él, y en el significado específico de este libro, ir más allá de la capacidad sostenible de soporte del ambiente. El sobrepasamiento está causado por retrasos o fallas en los procesos de retroalimentación informativa que impiden a un sistema que se controle así mismo con relación a sus límites. El sobrepasamiento es también una función de la capacidad de cambio o movimiento del sistema, un retraso en la retroalimentación que puede ser acomodada a baja velocidad, puede ocasionar un sobrepasamiento a mayor velocidad.

12 Donella Meadows, Daniel Meadon y Jorge Rander (1992) Más Allá de los Límites del Crecimiento. Informe del Club de Roma. El País - Aguilar. Madrid. pág. 30. 


\section{PRISTINIDAD ECOLÓGICA}

Asumimos nuevas valoraciones como el concepto de Pristinidad Ecológica constituida por los recursos biológicos y genéticos que no han sido alterados, que son fundamentales para conocer la evolución de la vida y su diversidad y cuya destrucción misma pueda generar graves consecuencias para la humanidad, incluyendo fuentes de alimentación, estabilidad global, el propio sostén de desarrollo, entendidos en términos de sustentabilidad. Son bienes ambientales insustituibles que deben ser preservados a perpetuidad. Podríamos decir que la pristinidad ecológica no posee equivalente en términos de la ecología clásica. Para el ecólogo Otto Huber, este concepto es relativamente nuevo, pero su importancia está creciendo rápidamente a nivel intertropical. La presencia de grandes y significativas extensiones de países no perturbados adquiere un valor económico cada día mayor, debido a su alarmante e irreversible reducción en casi todas las otras regiones tropicales, cuya importancia se hace cada día más evidente a nivel mundial y regional.

\section{PARQUES NACIONALES Y RESERVAS FORESTALES}

Un parque nacional es aquella porción del territorio, decretada por los estados, mediante un proceso ejecutivo o legislativo y que tiene por objeto proteger y conservar en forma integral y permanente el ambiente, su diversidad biológica, cultural y arqueológica atendiendo a las características ecológicas, geográficas, geológicas, históricas, culturales y a su belleza escénica natural y que posee especies de la flora y fauna de importancia nacional. El primer parque nacional fue creado en 1875 en Estados Unidos, el Parque Nacional Yelloswtone durante la presidencia de Ulises S. Grant, quien el 1 de marzo de 1875 dijo que «Yelloswtone constituye en los términos de la presente ley, una zona reservada donde no pueden establecerse asentamientos y que no se puede ocupar ni vender. El terreno está reservado para creación de un parque público o de una zona de descanso para beneficio y disfrute de la población».

Las reservas forestales son creadas por los Estados en terrenos baldíos y en otras propiedades de la nación cuando así lo requiera para fines forestales, constituidos por macizos boscosos, que por situación geográfica, composición cualitativa y cuantitativa florística o por ser las únicas disponibles en una zona, constituyen elementos indispensables para el movimiento de la industria forestal. Las reservas no pueden ser desafectadas sin previa aprobación de los organismos del Estado, normalmente el Parlamento. 


\section{ORDENACIÓN DEL TERRITORIO}

La Ordenación del Territorio es un principio que posee rango constitucional, un derecho y una obligación que establece que las autoridades deben incorporar las realidades ecológicas, geográficas, poblacionales, sociales, culturales, políticas, de acuerdo con las premisas del desarrollo sustentable, es también un instrumento de planificación a largo plazo que sirve de marco de referencia espacial a los planes de desarrollo de mediano y corto plazo del país, a los planes estadales y municipales de ordenación del territorio y a los planes sectoriales aprobados por el Estado.

La Ordenación del Territorio tiene como objetivo promover la localización adecuada de la población, la producción y la infraestructura del país, la preservación de determinados espacios como áreas naturales por sus características ecológicas con el fin de armonizar los criterios de desarrollo económico, defensa nacional, conservación ambiental y justicia social.

La Ordenación del Territorio en el marco de la sustentabilidad se propone el mejor uso del espacio geográfico en función de sus capacidades económicas, geopolíticas, ecológica, de seguridad y defensa del equilibrio demográfico.

Entre las categorías de uso del Plan de Ordenación Territorial se encuentran los centros nacionales y regionales, subregionales, infraestructura hidráulica, líneas ferroviarias, monumentos naturales, áreas agrícolas, áreas petroleras, reservas forestales, parques nacionales, refugios de flora y fauna silvestre, áreas turístico recreacionales, zonas de integración fronteriza decretadas por tratados internacionales.

\section{JUSTICIA ECOLÓGICA Y JUSTICA ECOANTROPOLÓGICA}

El concepto de Justicia Ecológica también subyacente en este trabajo, que reconoce la necesidad de una justicia social y económica que promueve mayor equidad y productividad, con el uso sustentable de la base de recursos nacional y planetaria. Asume una visión de largo plazo o de larga duración, que preserve los recursos biológicos-ecológicos como patrimonio colectivo transgeneracional. Ello supone una vinculación estrecha entre derechos humanos y derechos ecológicos.

A decir de la española Teresa Vicente Jiménez:

1. La dinámica de la justicia ecológica aparece limitada desde el comienzo por la inercia de los límites territoriales políticos, y 
ante todo, por la estructura interna del sistema político y administrativo sus límites de organización de poder, de planificación, de impulso, de gestión, al igual que los círculos de consumo de cuenta de aquellas funciones. La tendencia más dinámica consistirá en hacer que se correspondan el ambiente político administrativo con la plenitud y la integridad de unidad funcional del ecosistema.

2. La política ecológica podemos caracterizarla como aquella que trasciende el Paradigma Antropocéntrico, incorpore los elementos naturales como partes constitutivas del «acto justo». Se trata de una valoración que va más allá de los periodos temporales y requiere de una visión telescópica a los efectos de ponderar los intereses de las generaciones futuras.

3. El Futuro al que debe alcanzar la tutela sobre la ecología, no podría medirse por una sucesión limitada de generaciones.

4. El tiempo cósmico trasciende, y a la par integra, el tiempo de la historia.

5. La nueva visión ecocéntrica que muestra al ser humano y su realidad socioeconómica y cultural como un componente más del vasto sistema ecológico global.

6. Se revaloriza la noción de límite para la determinación de lo justo de lo debido en cuanto objeto de la justicia ecológica.

7. Los límites no significan un freno absoluto o la resignación y estancamiento respecto a la actividad humana, económica y cultural, «sino que consiste en el reconocimiento de los condicionamientos y las resistencias de las realidades físicas y biológicas que han de construir los proyectos de desarrollo». (Jiménez, 2002: $62-66)^{13}$.

En fin se trata de redefinir y ordenar en profundidad del hombre con la naturaleza y el universo ante el peligro de la tecnología ilimitada y de un medio natural finito y en muchos casos sin posibilidades de regeneración ya que muchos de los bienes son insustituibles.

\section{PRINCIPIO DE PRECAUCIÓN AMBIENTAL}

El Principio de Precaución Ambiental que obliga a los Estados y particulares a tomar las decisiones y mecanismos para evitar que se

13 Teresa Vicente Jiménez (2002) Justicia Ecológica y Protección al Medio Ambiente. Editorial Trota. Madrid. pág. 62-66. 
consuman daños graves al ambiente, aun sin tener toda la certeza científica sobre el problema. El principio $\mathrm{N}^{\circ} 15$ de la Declaración de Río 1992 -Cumbre de la Tierra ONU, quizás la Conferencia Internacional más importante de la historia de la humanidad, establece que en «los Estados deberán aplicar el criterio de precaución conforme a sus necesidades con el fin de proteger el medio ambiente»; la evaluación de impacto ambiental se incluye como intrínseca al desarrollo: «Deberá emprenderse una evaluación de impacto ambiental, en calidad de instrumento nacional, respecto a cualquier actividad propuesta que probablemente haya de producir un impacto negativo». Los estudios y evaluación de impacto ambiental han evolucionado de técnicas hasta consagrarse como disposiciones legales y constitucionales a tal punto que en los países industrializados es difícil concebir un proyecto industrial o de infraestructura sin haber realizado previamente un estudio de impacto ambiental.

Los criterios ecoantropológicos y transgeneracionales que deben acompañar los proyectos se establecen en la constitución con base al respecto de los procesos ecológicos esenciales, la diversidad de ecosistemas, especies y recursos geológicos, la protección del paisaje, las costas, los suelos, el agua y su ciclo hidrológico así como la identidad cultural y modo de vida.

Se asume igualmente los principios de participación política, solidaridad mundial, responsabilidad social y ecológica, consulta pública para los estados, y desarrollo sustentable, las cuales incorporamos como substrato teórico y ético de este trabajo.

\section{DEMOGRAFÍA SUSTENTABLE Y ECOLOGÍA HUMANA}

Debemos promover una Demografía Sostenible y Sustentable ${ }^{14}$. La Ecología Humana representa un enfoque interdisciplinario sobre las relaciones entre una población humana y su ambiente físico, político y socioeconómico. Así se interesa por los procesos de adaptación e inadaptación de una población humana.

${ }^{14}$ En 1972, Levi-Strauss sostuvo que para la humanidad o para cualquier otra especie viva «existe una densidad óptima y esta no puede ser demasiado baja, pues si lo fuera no habría comunicación y sobrevendría el estancamiento. Tampoco un exceso de población que genere dificultades en el consumo de recursos particularmente alimentos y desechos tóxicos». (Claude Levi-Strauss. Entrevistado por Willem L. Oltmans. Debates Sobre El Crecimiento FCE. México, 1973) 
Así por ejemplo en España este tema ha tenido una especial importancia, en virtud de que el proceso de despoblamiento en el medio rural, hecho que en España ha tenido una especial incidencia en los últimos treinta años, es uno de los problemas ambientales más importante con los que se enfrentan muchas de las comarcas: abandono de cultivos, con el crecimiento de malezas (mayor riesgo de incendios), aumento de la erosión, descuido y desaprovechamientos forestales tradicionales con el consiguiente abandono de zonas forestales, pérdida de ritos, costumbre y valores tradicionales, etc. Es por ello, que desde las administraciones se han de elaborar políticas tendientes a fijar las poblaciones en las zonas rurales, evitando el progresivo despoblamiento y abandono de las mismas ${ }^{15}$.

La Conferencia Internacional de Nairobi, en 1997, definió la desertificación como la «pérdida, a veces irreversible, del potencial biológico del suelo, a consecuencia de acciones antropogenicas».

\section{DESARROLLO SOCIAL INSUSTENTABLE}

Desde nuestro punto de vista la Sustentabilidad es una concepción, un nuevo paradigma que va más allá de un simple crecimiento. Incluye aspectos ecológicos, económicos, sociales y culturales. Supone resguardar los intereses de las presentes y futuras generaciones muy distantes de la visión de algunos economistas que utilizan el término sostenible en forma unilateral, limitada a la idea de crecimiento.

La Sustentabilidad posee su dimensión social sin la cual no puede realizarse. Entre los fundamentos y prerrequisitos del desarrollo social sustentable, podemos sintetizarlo, siguiendo las Conferencias de las Naciones Unidas sobre Ambiente y Desarrollo, celebradas en Río de Janeiro (1992) y la Cumbre sobre Desarrollo Social en Copenhague (1993).

$1^{\circ}$ El establecimiento de una nueva ética en el mundo, basada en el respeto a la diversidad cultural, étnica, ecológica; la promoción de los derechos humanos, la tolerancia y la solidaridad; la protección de «los valores comunes» del hogar y la familia; la seguridad humana.

$2^{\circ}$ La interacción armónica y equilibrada entre las dimensiones económica, social y ecológica del desarrollo, con prioridad en las personas.

15 José A. Arenas Muños (2000) Diccionario Técnico Jurídico del Medio Ambiente. Editorial McGraw Hill. Madrid. pág. 283. 
$3^{\circ} \mathrm{El}$ reconocimiento de la importancia del mercado y las inversiones privadas para el logro del desarrollo social; advirtiendo las limitaciones del mercado como árbitro económico en la adopción de decisiones económicas relacionadas con las soluciones a problemas como la pobreza y la conservación del ambiente.

$4^{\circ}$ La necesidad de la participación del sector privado y la sociedad civil, dentro de ésta se destaca el papel trascendental de los organismos no gubernamentales (ONG).

$8^{\circ}$ La garantía del derecho al trabajo y la protección de los derechos tradicionales de la tierra y otros recursos, de los indígenas, pescadores, pastores y campesinos.

$9^{\circ}$ Fortalecimiento y ampliación de los recursos de los municipios, ONG, universidades y otras Instituciones educativas, organizaciones comerciales, entre otros, con el objeto de que participen la planificación urbana. La descentralización es una condición indispensable para el desarrollo social.

$10^{\circ} \mathrm{La}$ Cumbre de Copenhague, hizo énfasis en la solución de la atomización y la exclusión social y en el fomento de la cooperación internacional para lograr la integración y el desarrollo social. A tales efectos la declaración señala que «la desintegración social es una experiencia contemporánea demasiado conocida». Delincuencia organizada, drogas ilícitas, tráfico de armas, la trata de mujeres y niños, conflictos étnicos, religiosos, guerras civiles, terrorismo y xenofobia, genocidios, matanzas, por motivos políticos, constituyen amenazas fundamentales para las sociedades y el orden social mundial. Son estas razones apremiantes y urgentes para que los gobiernos adopten medidas en forma individual y si cabe, conjunta, para fomentar la cohesión social, pero reconociendo, protegiendo y valorando al mismo tiempo la diversidad «este aspecto es de gran importancia en función de la tesis de que la crisis no es solo social y económica sino que es una crisis de orden civilizatorio que afecta las bases mismas de la vida sobre el planeta».

El desarrollo sustentable o sostenible demanda un cambio sustancial en los patrones de industrialización, producción, distribución, consumo y del comercio internacional, una nueva ética basada en la solidaridad humana y de la naturaleza y supone discutir la pertinencia de la tesis de un desarrollo centrado solamente en las personas.

Hoy se discute la necesidad de una solidaridad también con la diversidad de especies animales y vegetales, así como el uso de los recursos en el marco de una integración armónica entre lo social, lo 
económico y lo ecológico, fortaleciendo la perspectiva de los derechos transgeneraciones.

\section{COMERCIO SUSTENTABLE}

Asumimos el planteamiento sobre la necesidad de un comercio local e internacional sustentable teniendo presente que la temática comercio-ambiente ha sido incluido en las agendas de las Naciones Unidas desde la Conferencia sobre el medio humano de Estocolmo (1972) y el propio GATT hasta la creación de la Organización Mundial del Comercio y la Declaración de la Cumbre de la Tierra Río de Janeiro de 1992. El comercio internacional y local sustentable es aquel que tiende a preservar la biodiversidad y la base de recursos del planeta con principios, procedimientos, técnicas y productos sustentables. Supone asumir como meta «la responsabilidad ambiental» definida en los sistemas de gestión ambiental ISO-14000 y su base conceptual y operativa que incluye Administración Ambiental, Auditoria Ambiental, Evaluación del Ciclo de la Vida, Clasificación Ambiental, Desempeño Ambiental. (CA SCIO, Woodside, Mitchell 1997: 6) que tiene como fundamento de acuerdo global la organización $\mathrm{ISO}^{16}$.

La Internacional Organization For Standardization (ISO) tuvo sus comienzos después de la segunda Guerra mundial, es una organización no-gubernamental con sede en Ginebra con más de 100 agrupaciones o países miembros, aunque no está afiliada a las Naciones Unidas, los países están representados en ISO por autoridades designadas dentro de cada país. Organizaciones gubernamentales de EE.UU. como la U.S. Envinonmental Proteccion Agenay-Epa (Agencia de Protección Ambiental de Estados Unidos) son parte del Instituto Nacional Norteamericano de Normas) que es un organismo del sector privado. El Departamento de Energía (DOE) la Ocupational Safety End Heahy Administration-Osha (Administración para la seguridad y la salud laboral) son miembros de

${ }^{16}$ La Cámara Internacional de Comercio para la Administración Ambiental; ha elaborado un conjunto de principios. El N ${ }^{\circ} 1$ dice «Reconocer la Administración Ambiental entre las más altas prioridades corporativas y como un determinante clave para un desarrollo sustentable, establecer políticas, programas y prácticas para realizar operaciones ambientalmente correctas. Joseph Castin Gayle Woodside, Philip Mitchel en Las Nuevas Normas para la Administración Ambiental. Editorial McGraw Hill. México, Buenos Aires, Caracas, Madrid, New York, Sao Paolo, Hamburgo, Milán, San Francisco, Sydney, 1977». 
ANSI siendo por lo tanto miembro como ente multisectorial. ANSI es miembro de ISO, «aun cuando las normas son elaboradas para el sector privado y tienen un carácter voluntario, muchos organismos gubernamentales pueden decidir convertir una norma ISO en una disposición obligatoria o legal. Tales normas también pueden convertirse en condiciones para cerrar un negocio en transacciones comerciales, haciendo que las partes ya no las puedan considerar como voluntarias».

El comercio es parte del proceso de globalización planetaria que ha significado por un lado la interconexión intercivilizatoria pero también conectado a una idea de desarrollo insustentable que pone en peligro la vida sobre el planeta.

La sobreexplotación de los recursos naturales puede conducir a su extinción o en todo caso, a que su tiempo de renovación sea tan extremadamente largo, que pueden ser declaradas agotados.

Determinadas especies animales o vegetales, que al ser sometidos a una tasa de explotación intensa pueden convertirse en no-renovables.

Preservar los recursos va a depender en gran parte de la intensidad, el estilo tecnológico que se utilice y el conocimiento de la capacidad de carga y las características de los ecosistemas, especies y genes que conforman su biodiversidad.

Los recursos denominados renovables (aquellos que se auto generan en los procesos naturales); los forestales, el agua, el oxígeno, solo se logra su mantenimiento, cuando las tasas de consumo no superen las tasas de regeneración natural. Por ejemplo el agua dulce se produce de manera continua a través del ciclo natural, sin embargo su consumo y uso desmesurado ha provocado que en determinados lugares del planeta se convierta en un bien escaso, o con una pérdida creciente de su calidad. Es el mismo caso de los suelos, tal como se observa con el proceso de desertificación en el continente africano.

\section{TRANSVERSALIZACIÓN AXIOLÓGICA DEL AMBIENTE}

Se ha producido una trasversalización axiológica del ambiente en los convenios, declaraciones, protocolos, acuerdos, constituciones, leyes y políticas de los organismos internacionales, los estados y la dinámica económica y social global, adquieriendo un status teórico 
en las ciencias sociales, tal como lo señala Edgar Morin «Políticamente, la ecología era desconocida en 1965, fecha de la primera edición del libro «La Introducción a la Política del Hombre», y apenas asomaba la superficie invisible.

En este período se produjo, no solo la vinculación entre el pensamiento científico / ecología científica y la toma de conciencia de las degradaciones del ambiente local (lagos, ríos y ciudades) y del ambiente global, océanos, planeta, capaz de efectos sobre el conjunto de la vida, sino también se produjo una transición de la ciencia ecológica a la conciencia ecológica.

\section{CONCIENCIA ECOLÓGICA}

La conciencia ecológica nos exige un enfoque transdiciplinario que permita estudiar la complejidad antropo-socio-ecológica, y jurídica, incluida el conocimiento de las experiencias civilizatorias sobre el planeta: civilizaciones no-occidentales, indígenas, campesinos, civilización capitalista y su economía del mercado, o el modelo de la economía social y ecológica de mercado, socialismo de estado. En general se trata de analizar el proceso histórico mediante el cual la humanidad ha implantado modalidades societarias y civilizatorias, en una alta proporción, con graves impactos ambientales, sociales, globales y locales.

El desarrollo concebido únicamente como hecho teórico y económico es insostenible, incluyendo el propio desarrollo sostenible o sustentable, tal como lo señala Morin (2001) «es necesaria una noción más rica y compleja del desarrollo, que no sea solo material sino también intelectual, efectiva, moral».

Diferentes formas de uso de los recursos naturales desde el Imperio Romano, hasta las formas de explotación actuales han puesto en peligro el futuro de la humanidad, por lo cual se requiere superar la visión localista o el globalismo extremo. Pensar y actuar global y localmente al mismo tiempo, dentro de un paradigma que incluya incluso, una concepción interplanetaria o más allá de la globalización planetaria. Asumimos entonces, un pensamiento ecológico de gran complejidad, integrando conocimientos procedentes de distintas disciplinas: antropología, ecología, derecho, economía, sociología, geología, biología, física, geografía, entre otras, que dan nacimiento incluso a otras disciplinas o transdisciplinas. 


\section{BIENES JURÍDICOS AMBIENTALES}

Son los bienes comunes -res Comunes -que no pertenecen a nadie en particular, de uso común como el agua, el aire, la capa de ozono, el clima, los cuales tienen protección a través de las constituciones y leyes de los países y los convenios, tratados, protocolos y declaraciones internacionales, sin cuyas previsiones no seria posible la vida. Son bienes insustituibles, que van más allá de los bienes concebidos en los códigos civiles, que poseen casi siempre una definición prevalentemente económica.

Los Bienes Jurídicos Ambientales son patrimonio común e irrenunciable de la humanidad, tal como lo establecen las más modernas constituciones, aunque su administración corresponde al Estado en los territorios establecidos en la Constitución y los convenios internacionales ambientales. Así tenemos, que las aguas son, bienes del dominio público de la nación, que está en la obligación de proteger el ciclo hidrológico que es un fenómeno natural, pues esas aguas se encuentran en estado líquido, gaseoso y sólido tanto en mares, lagos, ríos, la atmósfera, las tuberías, siendo un bien colectivo y transgeneracional; debe ser utilizado con criterios de sustentabilidad, ordenación del territorio y justicia, a los efectos de garantizar su calidad (potabilidad), pureza para el consumo humano y de otras especies, y de las actividades sociales, económicas inherentes al proceso civilizatorio y sociohistórico. El ciclo hidrológico supone también la protección también de los bosques, los procesos ecológicos y físicos que contribuyen a la reproducción del ciclo del agua y de la vida, razón por la cual los parques nacionales y otras áreas bajo régimen de administración especial como las reservas forestales, reservas de biosfera, reservas hidrológicas, son protegidos por la constitución y las leyes.

Existen aguas como las del Desierto del Sahara, que poseen acuíferos no renovables cuyo agotamiento si se produce seria permanente, es un bien ambiental insustituible no reproducible. 